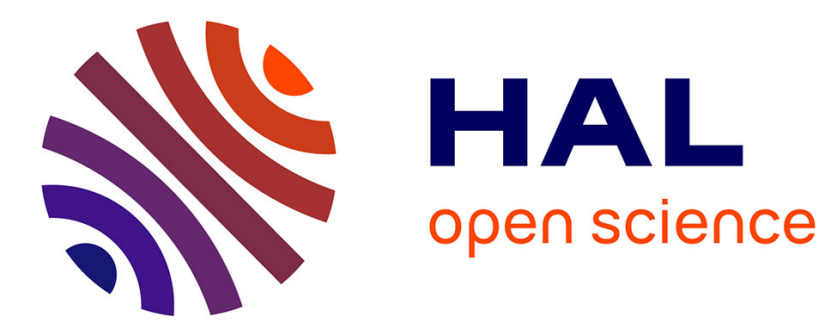

\title{
Heterogeneity in the allocation of reintroduction efforts among terrestrial mammals in Europe
}

Charles Thévenin, Aïssa Morin, Christian Kerbiriou, François Sarrazin, Alexandre Robert

\section{- To cite this version:}

Charles Thévenin, Aïssa Morin, Christian Kerbiriou, François Sarrazin, Alexandre Robert. Heterogeneity in the allocation of reintroduction efforts among terrestrial mammals in Europe. Biological Conservation, 2020, 241, 10.1016/j.biocon.2019.108346 . mnhn-02553941

\section{HAL Id: mnhn-02553941}

\section{https://hal-mnhn.archives-ouvertes.fr/mnhn-02553941}

Submitted on 24 Apr 2020

HAL is a multi-disciplinary open access archive for the deposit and dissemination of scientific research documents, whether they are published or not. The documents may come from teaching and research institutions in France or abroad, or from public or private research centers.
L'archive ouverte pluridisciplinaire HAL, est destinée au dépôt et à la diffusion de documents scientifiques de niveau recherche, publiés ou non, émanant des établissements d'enseignement et de recherche français ou étrangers, des laboratoires publics ou privés. 
2 Heterogeneity in the allocation of reintroduction efforts among

3 terrestrial mammals in Europe.

4

5 Charles Thévenin, Aïssa Morin, Christian Kerbiriou, Francois

6 Sarrazin, Alexandre Robert.

8 Biological Conservation, Elsevier, 2020, 241, pp.108346.

9

10

11 Abstract

12

13

14

15

16

17

18 allocation of reintroduction efforts at large scale generally consider taxonomic bias within and

19 among higher taxa (e.g. vertebrates, plants), by comparing the number of reintroduced species

20 within a taxon to its prevalence in nature. Here, we show that the bias is even more striking

21 when accounting for the differences in the number of implemented programs among 
22 reintroduced species. We conducted a comprehensive search of the peer-reviewed and grey

23 literature to inventory reintroduction programs of European terrestrial mammals. We identified 2428 species that have been reintroduced at least one time. For each reintroduced mammal, we 25 extensively searched two literature search engines and found 414 relevant publications, which 26 described 375 distinguishable reintroduction programs implemented in Europe from the early $2720^{\text {th }}$ century to 2013 . We used the number of implemented programs and the number of 28 associated publications to investigate the distribution of reintroduction efforts among species. 29 Our results show a substantial heterogeneity in the allocation of reintroduction efforts, with $3068 \%$ of implemented reintroductions in Europe involving only three species: the beaver (Castor 31 fiber), the Alpine ibex (Capra ibex) and the European bison (Bison bonasus). 


\section{Introduction}

Biodiversity is under more severe threats than perceived when considering population declines and losses, rather than focusing only on species extinction (Ceballos, Ehrlich, \& Dirzo, 2017). Effective conservation strategies are therefore required to reverse the dramatic shrinkage in species' geographical ranges, in order to support evolutionary trajectories in biological systems, as well as sustainable ecosystem functioning and services (Sarrazin \& Lecomte, 2016).

Reintroduction is the process of re-establishing a population in the indigenous range of a species where it has been extirpated (IUCN/SSC, 2013). Reintroduction is a popular restoration tool, as it moves towards the proactive return of locally extinct species into the wild if protective measures are not sufficient to ensure the return of the species. Reintroductions have been used for over a century, and the number of implemented programs, as well as the number of species involved have increased over the past decades (Seddon, Armstrong, \& Maloney, 2007; Swan et al., 2016).

One interesting question in reintroduction biology is whether the accumulation of local reintroduction efforts have the potential to benefit to a wide array of threatened biodiversity at large taxonomic scale, which is not possible if most programs focus on, e.g., a few charismatic species. Using a database of reintroduction programs worldwide, yielding a total of 699 reintroduced species of plants and animals, Seddon, Soorae \& Launay (2005) showed that vertebrate species were over-represented with respect to their prevalence in nature. Among them, reintroduced species were mostly mammals and birds, whereas fish were underrepresented. More recently, similar biases within reintroduced mammals in Europe was uncovered, with a disproportionate list of reintroduced Carnivores and ungulates relative to their prevalence in the European assemblage of terrestrial mammals (Thévenin et al., 2018). These studies showed that reintroduction efforts are taxonomically and phylogenetically 
clustered within mammals, which is necessary to appreciate potential biases in reintroduction efforts. However, these studies focussed on the distinction between those species that have been reintroduced (at least once) vs. those that have not been reintroduced, without consideration for actual numbers of programs for each species. Here we provide a more in-depth look at the distribution of the number of implemented reintroduction programs per species. We focused on the list of 28 species of European terrestrial mammals that we identified as reintroduced at least once (Thévenin et al. 2018). For each species, we searched the ISI Web of Knowledge database and used Google Scholar search engine to identify reintroduction programs implemented over the past century. We described the heterogeneity in the implementation of population restoration programs and their reporting among European reintroduced mammals. The dataset we compiled allowed to explore the temporal and geographic distribution of reintroduction efforts in Europe.

\section{Materials and Methods}

Our primary objective here was to make an inventory of reintroduction "programs" aiming at re-establishing viable populations. Conceptually, we define a "population" based on the common biological meaning of the term i.e., a group of organisms of the same species occupying a particular space at a particular time and interacting more with each other than with individuals of the same species located at a distance they cross only through rare dispersal events (see Berryman, 2002, for a general discussion, and Robert et al al..2 201므, in the context of conservation translocations). This theoretical definition of a population is of course associated with practical difficulties in defining the boundaries of populations in the field, particularly for species with continuous distribution or where distribution data are missing. These difficulties 
are particularly important in our study regarding the aggregation (or separation) of reintroduction programs, and also in the case of metapopulations. We consider here that individual reintroduction programs are defined at the population level. In other words, each program aims to create a population, even when that population is part of an identified metapopulation. At the population organizational level, only reintroductions are considered (i.e. attempts to restore an extinct local population), although the program could be considered as a "reinforcement" at the metapopulation level. Intended reintroductions were not included (e.g., feasibility studies with no indication that individuals were released). We performed a comprehensive search (Swan et al., 2016) of the reintroduction and translocation-related literature to identify past and ongoing reintroduction programs implemented in the European subcontinent, including the western part of Russia and excluding Turkey. Using the list of 28 previously identified reintroduced species among the IUCN list of 202 native European terrestrial mammals (Thévenin et al., 2018), we performed independent queries for each species using the ISI Web of Science database, including all indexed peer reviewed literature. Because substantial information about translocation programs can be found in the grey literature, we also run each query on Google Scholar and searched for additional references in the first 50 records. We performed this search in the spring of 2016 and considered all published records available online up to May $1^{\text {st }}, 2016$. Our search terms were selected to maximize specificity at the expense of sensitivity, in order to focus on reintroductions and avoid publications relating to reinforcements of existing populations or mitigation translocations used to manage humanwildlife conflicts (Table 1). To account for potential taxonomic revisions over time and the fact that the species' name used by the authors at the time of publication may no longer correspond to the current name, the species search terms included both the Latin name and English common name along with all relevant synonyms available on the "Taxonomy" section of the Species Fact Sheet provided by the IUCN Red List website (available at www.iucnredlist.org). For 
108 example, the species search terms used for identifying translocations of Water voles (Arvicola

109 amphibius) included the following terms: "European Water Vole" OR "Eurasian Water Vole" 110 OR "Water Vole" OR “Arvicola amphibius" OR “Arvicola terrestris" OR "Mus amphibius".

111

112 
113 Table 1: List of the terms used to identify reintroduction programs for native terrestrial

114 mammals in Europe

\begin{tabular}{lc}
\hline Category & Search Term \\
\hline Species & Latin name OR synonym(s) OR Common name(s) \\
\hline Translocation & reintroduc* OR re-introduc* OR translocat* OR re- \\
& establish* Or releas* OR relocat* \\
AND & \\
Motive & population* OR conserv* OR restorat*
\end{tabular}

AND

Location $\quad$ Europe*

115 Terms were used in the ISI Web of Science database and Google Scholar search engine to

116 identify documented reintroduction programs. *Indicates the use of a wildcard; for example,

117 reintroduc* can refer to reintroduction OR reintroductions OR reintroduce OR reintroduces

118 OR reintroduced OR reintroducing.

121 We accurately screened each publication to determine which publications were relevant, that

122 is, which described at least one program of translocation and release of individuals that we

123 considered to be a reintroduction based on the intent and location of releases, i.e. the attempt to

124 re-establish a free-ranging population in the former range of the species where it has been 
extirpated (IUCN/SSC, 2013). Reintroductions of mammals often involve game species

126 (Griffith et al., 1989), and it was sometimes difficult to fully grasp whether the main purpose

of the translocation would lean towards species exploitation rather than long-term conservation.

Reintroductions of potential game species were included when they clearly aimed at restoring

a viable population in the wild. Other cases where conservation did not seem to be the primary

objective of releases were considered as restocking translocations and not integrated in our data

131 (Supplementary Information, Table S1). Sometimes the full text was not accessible, but we

132 included the publication if we could unambiguously extract all relevant and necessary

133 information from the abstract. If a publication describing a reintroduction failed to provide the

134 basic information (e.g., approximate year of first release) but explicitly mentioned other

135 publications containing complementary information regarding the program, we extended our

136 search to such cited literature. Some publications mentioned or described multiple reintroduction programs for a single species, usually reviewing the recovery of the focal species

138 through time (e.g., Biebach \& Keller, 2012). In such cases we considered the list of programs

139 as described in these publications. Most of the publications we screened focused on a single

140 species, with only seven publications mentioning or describing reintroduction programs for

141 more than one species.

142 For each relevant publication, we extracted the year of publication, the species translocated, the

143 approximated year of first release, and both the country and location of releases. The location

144 of releases refers to the most precise sub-national geographic area encompassing the

145 translocation site, and the level of precision varied substantially between publications (e.g.,

146 province, national park, nearest town). Some publications did not provide a precise date of first

147 release, but rather a time interval, for which, in the absence of additional information, we

148 deduced the year of first release as the middle of the given period (e.g., if individuals were

149 "released in the 1970s", we considered the first year of release to be 1975). In some cases, 
multiple releases were clustered into a single reintroduction program if we deemed the different

151 release events to contribute to the same population unit, based on the location of releases and expected home range of the species.

153

154

155

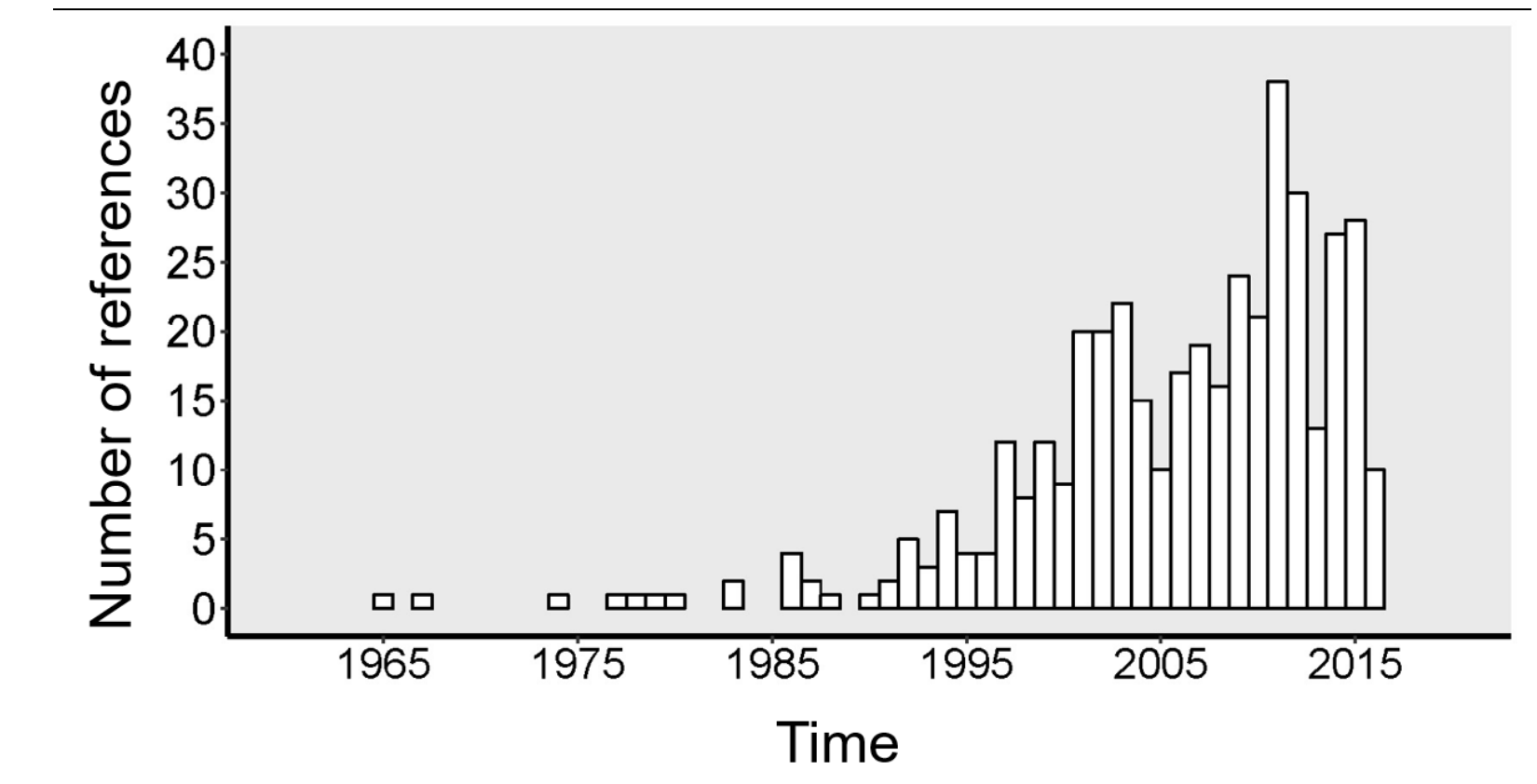

\section{Results}

Our searches on Web of Science yielded 1665 unique references, and we found 318 relevant references that described reintroduction programs precisely enough (year of first release, country and location of release site). We found 96 additional relevant references through our search on Google Scholar, or by extending our search to the cited references of some articles. These 414 publications, published between 1965 and March 2016, described 375 distinguishable reintroduction programs implemented between 1910 and 2013. The number of relevant publications increased over the past 30 years (Fig. 1). Reintroductions programs were implemented in 28 European countries, and most of these programs were undertaken in Switzerland (61), France (41), the United Kingdom (41) and Poland (36) (Fig. 2).

64 


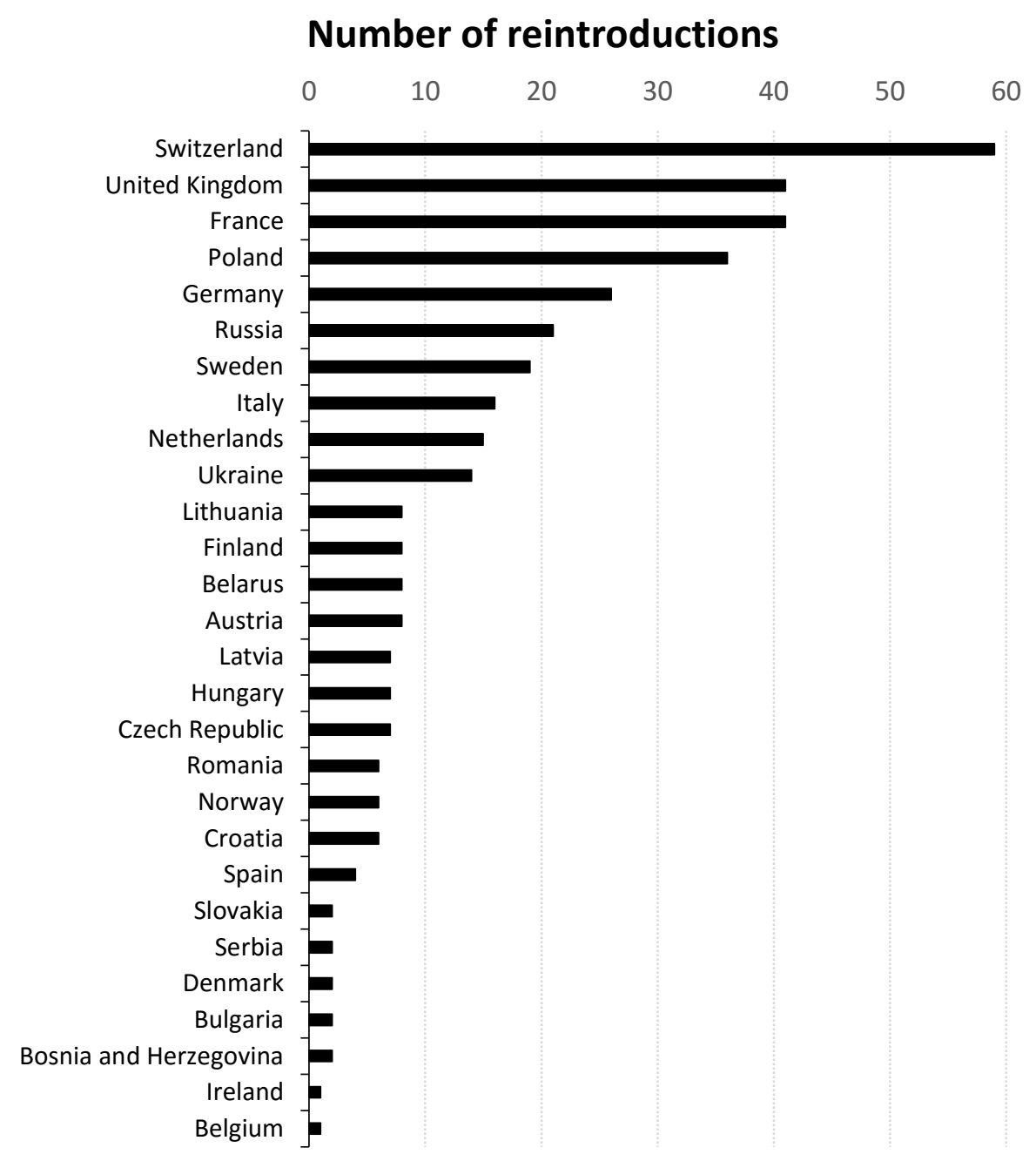

171 Fig. 2: Number of reintroduction programs by countries in the European subcontinent.

173 The allocation of reintroduction efforts per species was highly heterogeneous, with the number

174 of programs ranging from only one reintroduction up to 164 (Fig. 3). Only six out of 28 species

175 were involved in more than ten reintroduction attempts, and the median number of

176 reintroduction programs per species was three. The beaver was the most reintroduced mammal 
177 in Europe and has been involved in more than $40 \%$ of all the reintroduction attempts we

178 identified, followed by the Alpine ibex (54 programs, 14\%) and the European bison (39

179 programs, 10\%). The reporting effort per species was evaluated by considering the ratio of the

180 number of publications over the number of programs for each species. Low values of this ratio

181 indicate that relatively few publications described numerous reintroduction programs. This was

182 the case for the 5 most reintroduced species in our dataset (Castor fiber, Capra ibex, Bison

183 bonasus, Muscardinus avellanarius, Arvicola amphibius), with the lowest ratio being the

184 Alpine ibex with 54 reintroduction attempts described using only 15 publications (ratio $=0.28)$.

185 In contrast, some species have generated a substantial amount of publications relative to the

186 number of releases, as exemplified with 5 reintroduction programs of brown bears (Ursus

187 arctos) being described in 27 publications (ratio $=5.4$ ). At higher taxonomic level, the

188 distribution of reintroduction programs and associated references within the different orders of 189 terrestrial mammals of Europe is significantly different from that expected on the basis of the 190 number of described species in each order $\left(X^{2}=506.68\right.$, d.f. $=5, P<0.001 ; X^{2}=379,55$, d.f. $=$

$1915, P<0.001$; respectively) (Fig. 4). Closer examination of taxa reveals that Artiodactyla is 192 clearly over-represented both in terms of implemented programs and associated publications 193 (Pearson residuals of +18.77 and +9.91 , respectively). On the other hand, the Carnivora order 194 shows a contrasting pattern: Carnivores are slightly under-represented when considering the 195 number of implemented programs (Pearson residuals of -2.32) but are over-represented when 196 considering the associated publications (Pearson residuals of $+11,82$ ) (Fig. 4). 


\section{Number of reintroductions/references}

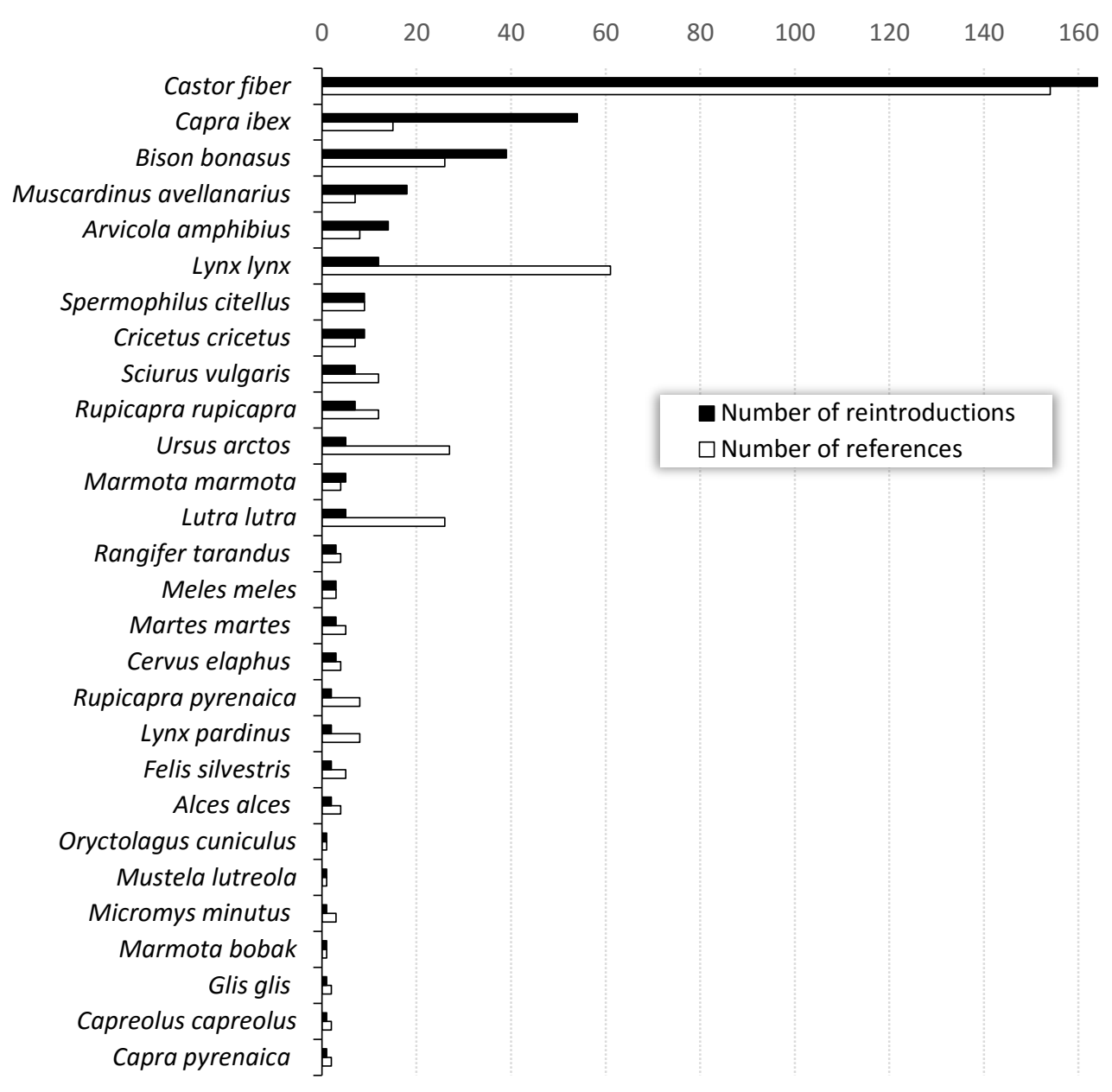

199 Fig. 3: Number of reintroduction programs (black bars) and associated references (white

200 bars) for the 28 terrestrial mammals reintroduced in Europe. Because some publications

201 described reintroductions for different species, the total number of references here is larger

202 than the number of unique references. 


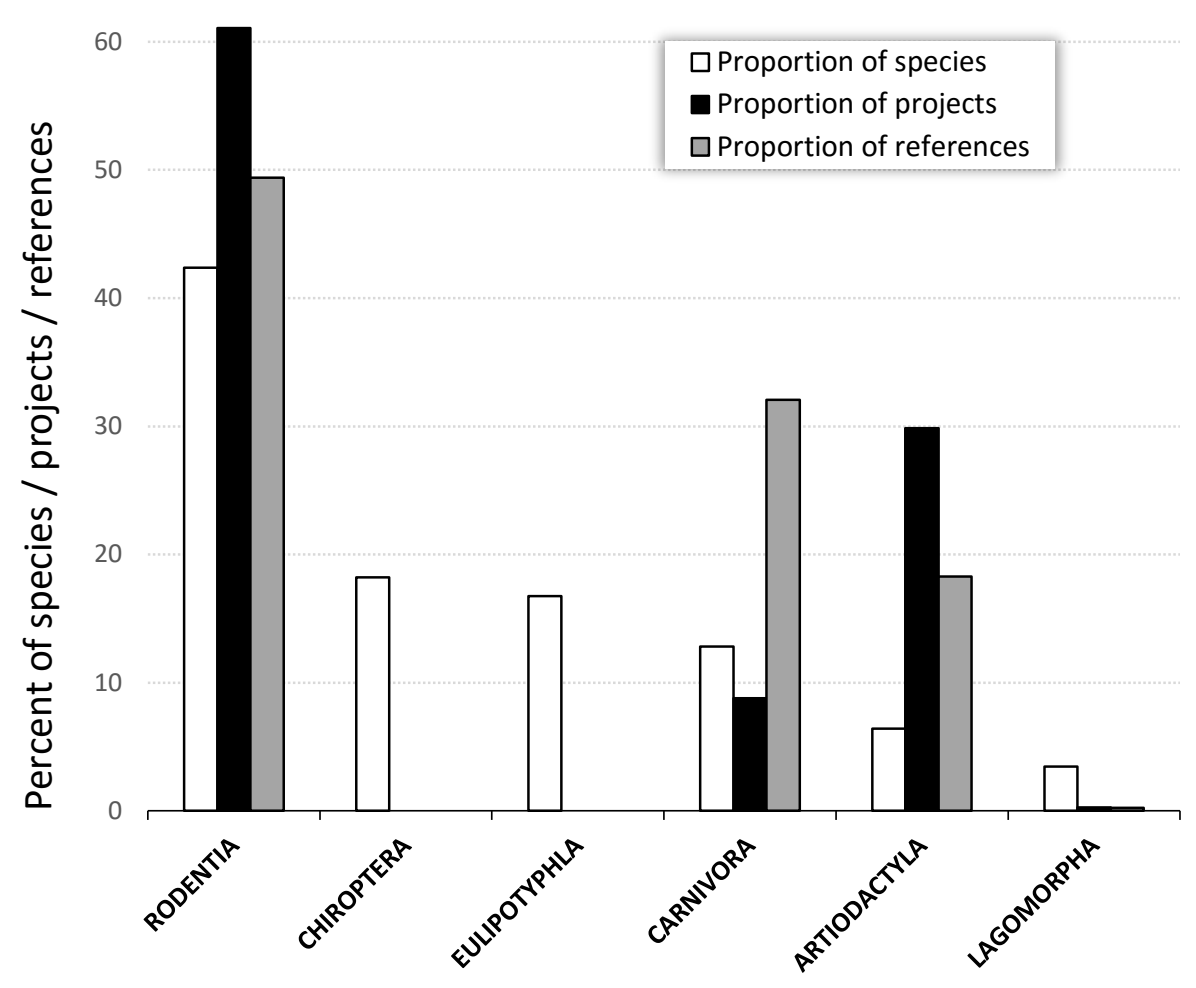

Fig. 4: Proportion of species out of the 202 European terrestrial mammals per taxonomic order (white bars) compared to the proportion of reintroduction programs (black bars) and the proportion of associated references (grey bars). into Epping Forest, Ireland, in 1910 (MacKinnon, 1978), and the reintroduction of the Alpine

211 ibex in Graue Hoerner, Switzerland, which started in 1911 (Stüwe \& Nievergelt, 1991; Biebach $212 \&$ Keller, 2012). The number of reintroduction programs has increased throughout the time 213 period (Fig. 5a), and the apparent diminution in the number of reintroduction programs from 2142006 onward can be attributed to a time lag between releases, data collection and any associated 215 publication (Fazey, Fischer, \& Lindenmayer, 2005; Swan et al., 2016). For most of the first half 216 of the $20^{\text {th }}$ century (up to the late 1950 s), reintroductions of terrestrial mammals in Europe 217 mainly involved beavers or Alpine ibex (51 and 28 programs respectively, out of 86 ). The other 
218 species reintroduced in this time period were the above mentioned red squirrel, the elk (Alces 219 alces; Schönfeld, 2009; Świsłocka et al., 2013), the brown bear (Buchalczyk, 1980) and the 220 reindeer (Rangifer tarandus; Røed et al., 2014). When considering the three mostly 221 reintroduced species in our data, we can see that beavers have benefited from a consistent and 222 continuous reintroduction effort throughout the entire time period considered (Fig. 5b). 223 Reintroductions of Alpine ibex mostly occurred in the first half of the time period (the last 224 release in our dataset occurred in 1995), with a cluster of programs around the centre of the 225 study period (1950-1970) (Fig. 5c). Most of the restoration of free-ranging populations of the 226 European bison took place in the past 60 years (Krasińska \& Krasiński, 2013) (Fig. 5d). 


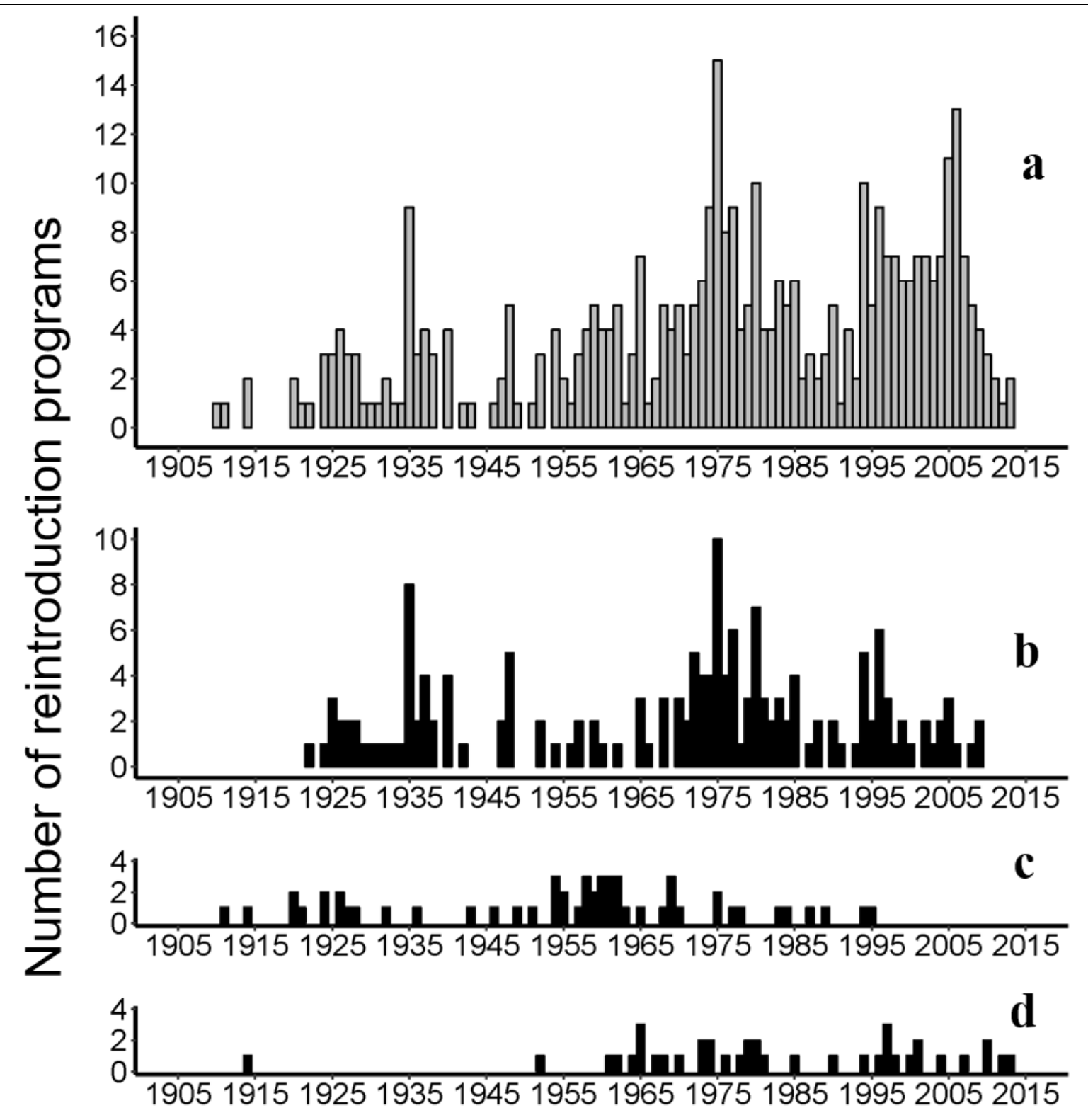

\section{Time}

229 Fig. 5: (a) Temporal distribution of reintroduction programs of 28 species of native

230 terrestrial mammals in Europe $(n=375)$; (b) reintroduction programs of beavers $(n=164)$;

231 (c) reintroduction programs of Alpine ibex $(n=54)$ and $(d)$ reintroduction programs of

232 European bison $(n=39)$. The distribution of reintroduction programs is based on

233 approximated date of first release. 


\section{Discussion}

237 Previous studies have shown that the allocation of reintroduction efforts is taxonomically (and phylogenetically) clustered by focussing on the distinction between those species that have been reintroduced (at least once) vs. those that have not been reintroduced (Seddon et al. 2005, Thévenin et al. 2018). Here we show that this heterogeneity is more striking when accounting

241 for the number of implemented programs among reintroduced species.

242 The most reintroduced species in our dataset are the beaver, the Alpine ibex and the European 243 bison, for which the main cause of population extirpation was overhunting (Stüwe \& 244 Nievergelt, 1991; Pucek et al., 2004). Of all reintroduced mammals, the remarkable recovery 245 of European beavers presumably benefited from widespread reintroductions. At the end of the $24619^{\text {th }}$ century, the species was reduced to about 1200 individuals scattered in 8 small relict 247 populations and would have been listed then as critically endangered (Halley, Rosell, \& 248 Saveljev, 2012). Reintroductions started in 1922 in Sweden and were later implemented in 20 249 other European countries. Early successes with remarkably little planning or monitoring 250 confirmed the beaver as a reliable candidate for reintroductions, and may have triggered a self251 reinforcing feedback for more implementations of programs over the years (Halley \& Rosell, 2002). Such self-reinforcing feedbacks where early reintroduction success may foster the implementation of new programs for some species may further contribute to the heterogeneity

254 of restoration efforts among species. Incentives for restoring viable populations of beavers were 255 initially associated to fur-harvesting and future economic gains, and later reintroductions 256 became more motivated by ecosystem management reasons. The beaver is considered a key257 stone species, which substantially impacts the structure and dynamics of aquatic ecosystems at 258 the landscape level. Beaver's dams influences the hydrology of surrounding areas, thus altering nutrient cycles and subsequently modifies the structure of invertebrate and plant communities 
260 (Macdonald et al., 1995). Such prominent and well-documented functional role of the species 261 in its recipient ecosystem may have played a role in the disproportionate, large scale effort that 262 was invested into its restoration.

263 Considering the number of implemented programs allows to reinterpret reintroduction biases 264 between mammalian orders in Europe. A previous study has shown that, among mammals, 265 Carnivores and Ungulates are over-represented in reintroduction efforts at a worldwide scale 266 (Seddon, Soorae, \& Launay, 2005). More than half of the reintroduced species of mammals in 267 Europe are members of the Artiodactyla or the Carnivora orders, although these orders represent 268 less than $20 \%$ of species in the European assemblage of native mammals (Thévenin et al. 2018). 269 However, when accounting for the number of implemented programs, the pattern is clearly 270 maintained for ungulates (30\% of implemented programs), but Carnivores are no longer over271 represented (8\% of implemented programs). One interesting finding of this study is that 272 reintroduced Carnivores seem to benefit from a higher reporting effort.

273 Our results show that some reintroduced species are relatively more reported in the literature.

274 The species with the most imbalanced ratio of the number of publications over the number of 275 associated publications are the Eurasian lynx (Lynx lynx), the brown bear and the otter (Lutra 276 lutra). Predators are charismatic species that are often employed in conservation because they 277 can easily gather public interest (i.e., "flagship species", sensu Simberloff 1998), and such 278 societal preferences may influence the choice of study species and lead to more publications. 279 Even though large carnivores are now recovering throughout Europe thanks to favourable 280 legislation and increases in prey availability (Chapron et al., 2014), the reintegration of such 281 large predators comes with many challenges that may require making adjustments to the 282 practices of some sectors like livestock farming, forestry or hunting (Breitenmoser et al., 2010; 283 Boitani \& Linnell, 2015). Restoring populations of large predators where they have been 284 extirpated constitutes a major challenge if adaptations to coexistence have been lost and if 
husbandry practices have evolved. Reintroductions of top predators can have economic costs 286 (e.g., predation on livestock) and trigger social conflicts that need to be carefully addressed and managed (Stahl et al., 2001), which is likely to generate additional research and publications.

Our search of the literature is certainly not exhaustive, but we believe that our data provide a good and representative proxy of the allocation of reintroduction efforts for European terrestrial mammals. Publication biases in conservation and reintroduction research have been documented, and show that some species receive disproportionate attention, and that successful translocations are more likely to be published than failed ones or those with uncertain outcomes (Fischer \& Lindenmayer, 2000; Clark \& May, 2002; Fazey, Fischer, \& Lindenmayer, 2005; Bajomi et al., 2010; Miller, Bell, \& Germano, 2014; Troudet et al., 2017). While our results provide a highly indicative description of reintroduction efforts for native European terrestrial mammals, we acknowledge that our data on reintroduction programs partly reflect publication effort and are likely to underestimate the number of programs implemented throughout Europe.

Another issue lies in the access to past publications, and how terminology evolved over the years. Some documentation of reintroduction attempts implemented several decades ago may have yet to be digitalized and indexed, and programs that have been recently implemented might not have yet been described in the literature. Additionally, reporting of reintroduction efforts at a continental scale is challenged by gaps and heterogeneity in the collection and compilation of information related to restoration attempts. First, language may greatly influence the spatial distribution of our European data. We only considered sources written in English, and we suspect that we might have missed a substantial amount of information written in the native language of the reintroduction team. For example our search yielded 4 reintroduction programs in Spain over the last century, while Perez et al. (2012), who conducted an extensive 308 review of translocation programs in Spain, taking into account Spanish language 309 documentation, found 9 translocation programs implemented from 1996 onwards. Studies have 
shown that the availability of information on biodiversity is unevenly distributed around the

311 world (Boakes et al., 2010), and that data availability is positively associated with country

312 wealth and the proportion of English speakers (Amano \& Sutherland, 2013). The high number

313 of reintroductions found in the United Kingdom can also be explained by insularity, as species

314 will have lower probabilities of natural recolonization after extinction, so that reintroduction

315 becomes a valuable conservation option. The spatial distribution of our data is also greatly

316 influenced by previous compilations and reviews of reintroduction programs in some areas. For

317 example, 48 out of the 59 reintroductions identified in Switzerland involved the Alpine ibex,

318 and 40 of these were mentioned in Biebach \& Keller (2012). Similarly, 23 out of the 36

319 reintroduction programs we identified in Poland involved the beaver, which were all mentioned

320 in one study on the expansion of the species in Europe by Kasperczyk (1987). Another source

321 of variability in the spatial distribution of mammal reintroductions in Europe could be the list

322 of nationally extinct mammals in European countries. Such conservation priorities at the

323 national scale could further shape the distribution of reintroduction efforts at the continental

324 scale.

325 In this study we used the number of implemented programs and the number of associated 326 publications to estimate the reintroduction effort per species. This is only one way to assess 327 how efforts are distributed in population restoration programs, and further studies are needed 328 to explore other aspects such as the financial costs of programs, information on release 329 strategies (number of individuals and number of release events), or how much effort was 330 invested to insure habitat quality before release.

331 Over the past 30 years, the development of reintroduction biology has advocated for an 332 improvement of reintroduction practice and implementation. Managers need to collect and use 333 all available information to improve reintroduction design and benefit from knowledge 334 accumulated through past attempts to restore populations (Sarrazin \& Barbault, 1996; Ewen \& 
336 therefore to enhance the documentation and transmission of knowledge from past 337 reintroduction programs. Some species, or groups of species (e.g. Carnivores) of mammals have 338 benefited from reviewing efforts describing and inventorying reintroduction programs in 339 Europe (Stüwe \& Nievergelt, 1991; Halley \& Rosell, 2002; Clark, Huber, \& Servheen, 2002; 340 Krasińska \& Krasiński, 2013). Our data constitute a core contribution to the development of a 341 webdatabase inventorying conservation translocation programs in Europe and the

342 Mediterranean basin which will promote standardization in reintroduction reporting to improve 343 their adaptive management (TRANSLOC webdatabase program, 344 http://translocations.in2p3.fr/).

345 The reintroduction of wild mammals and particularly ungulates often emerges as a cornerstone 346 in rewilding initiatives (Pettorelli et al., 2018; Pettorelli, Durant, \& du Toit, 2019), especially 347 in heavily anthropized landscapes such as Europe (Pedersen et al., 2019). In the rewilding 348 framework, motivations for conservation translocations shift from species-centred actions 349 towards the restoration of ecological and evolutionary processes at the ecosystem level, e.g., 350 through trophic rewilding (Svenning et al., 2016; Bakker \& Svenning, 2018; Perino et al., 351 2019). While further advances in the definition of rewilding and its distinction from ecological 352 restoration are needed (Derham, 2019; Hayward, Jachowski, et al., 2019; Hayward, Scanlon, et 353 al., 2019), the evaluation of past reintroduction efforts and understanding of their outcomes will 354 necessarily benefit to any future program aiming at restoring wildness, i.e. functional and 355 evolutionary potential in previously altered ecosystems. 


\section{References}

Amano, T., \& Sutherland, W. J. (2013). Four barriers to the global understanding of biodiversity conservation: wealth, language, geographical location and security. Proc. R. Soc. B 280, 20122649.

Armstrong, D. P., \& Seddon, P. J. (2008). Directions in reintroduction biology. Trends in Ecology \& Evolution 23, 20-25.

Bajomi, B., Pullin, A. S., Stewart, G. B., \& Takács-Sánta, A. (2010). Bias and dispersal in the animal reintroduction literature. Oryx 44, 358-365.

Bakker, E. S., \& Svenning, J.-C. (2018). Trophic rewilding: impact on ecosystems under global change. The Royal Society.

Berryman, A. A. (2002). Population: a central concept for ecology? Oikos 97, 439-442.

Biebach, I., \& Keller, Lukas. F. (2012). Genetic variation depends more on admixture than number of founders in reintroduced Alpine ibex population. Biological Conservation 147, 197-203.

Boakes, E. H., McGowan, P. J. K., Fuller, R. A., Chang-qing, D., Clark, N. E., O’Connor, K., \& Mace, G. M. (2010). Distorted Views of Biodiversity: Spatial and Temporal Bias in Species Occurrence Data. PLOS Biology 8, e1000385.

Boitani, L., \& Linnell, J. D. C. (2015). Bringing Large Mammals Back: Large Carnivores in Europe. In Rewilding European Landscapes. pp. 67-84. Springer, Cham.

Breitenmoser, U., Ryser, A., Molinari-Jobin, A., Zimmermann, F., Haller, H., Molinari, P., \& Breitenmoser-Würsten, C. (2010). The changing impact of predation as a source of conflict between hunters and reintroduced lynx in Switzerland. Biology and conservation of wild felids 493-506.

Buchalczyk, T. (1980). The Brown Bear in Poland. Bears: Their Biology and Management 4, 229-232. 
Ceballos, G., Ehrlich, P. R., \& Dirzo, R. (2017). Biological annihilation via the ongoing sixth mass extinction signaled by vertebrate population losses and declines. PNAS 201704949.

Chapron, G., Kaczensky, P., Linnell, J. D. C., Arx, M. von, Huber, D., Andrén, H., LópezBao, J. V., Adamec, M., Álvares, F., Anders, O., Balčiauskas, L., Balys, V., Bedő, P., Bego, F., Blanco, J. C., Breitenmoser, U., Brøseth, H., Bufka, L., Bunikyte, R., Ciucci, P., Dutsov, A., Engleder, T., Fuxjäger, C., Groff, C., Holmala, K., Hoxha, B., Iliopoulos, Y., Ionescu, O., Jeremić, J., Jerina, K., Kluth, G., Knauer, F., Kojola, I., Kos, I., Krofel, M., Kubala, J., Kunovac, S., Kusak, J., Kutal, M., Liberg, O., Majić, A., Männil, P., Manz, R., Marboutin, E., Marucco, F., Melovski, D., Mersini, K., Mertzanis, Y., Mysłajek, R. W., Nowak, S., Odden, J., Ozolins, J., Palomero, G., Paunović, M., Persson, J., Potočnik, H., Quenette, P.-Y., Rauer, G., Reinhardt, I., Rigg, R., Ryser, A., Salvatori, V., Skrbinšek, T., Stojanov, A., Swenson, J. E., Szemethy, L., Trajçe, A., Tsingarska-Sedefcheva, E., Váňa, M., Veeroja, R., Wabakken, P., Wölfl, M., Wölfl, S., Zimmermann, F., Zlatanova, D., \& Boitani, L. (2014). Recovery of large carnivores in Europe's modern human-dominated landscapes. Science 346, 1517-1519.

Clark, J. A., \& May, R. M. (2002). Taxonomic Bias in Conservation Research. Science 297, $191-192$.

Clark, J. D., Huber, D., \& Servheen, C. (2002). Bear reintroductions: lessons and challenges. Ursus 335-345.

Derham, T. T. (2019). In defence of 'rewilding' - a response to Hayward et al. (2019). Biological Conservation.

Ewen, J. G., \& Armstrong, D. P. (2007). Strategic monitoring of reintroductions in ecological restoration programmes. Ecoscience 14, 401-409. 
408 Fazey, I., Fischer, J., \& Lindenmayer, D. B. (2005). What do conservation biologists publish? Biological Conservation 124, 63-73.

410 Fischer, J., \& Lindenmayer, D. B. (2000). An assessment of the published results of animal relocations. Biological conservation 96, 1-11.

Griffith, B., Scott, J. M., Carpenter, J. W., \& Reed, C. (1989). Translocation as a species conservation tool: status and strategy. Science $\mathbf{2 4 5}, 477-480$.

Halley, D. J., \& Rosell, F. (2002). The beaver's reconquest of Eurasia: status, population development and management of a conservation success. Mammal review 32, 153178.

Halley, D., Rosell, F., \& Saveljev, A. (2012). Population and distribution of Eurasian beaver (Castor fiber). Baltic Forestry 18, 168-175.

Hayward, M. W., Jachowski, D., Bugir, C. K., Clulow, J., Krishnamurthy, R., Griffin, A. S., Chalmers, A. C., Linnell, J. D., Montgomery, R. A., \& Somers, M. J. (2019). The search for novelty continues for rewilding. Biological Conservation.

Hayward, M. W., Scanlon, R. J., Callen, A., Howell, L. G., Klop-Toker, K. L., Di Blanco, Y., Balkenhol, N., Bugir, C. K., Campbell, L., Caravaggi, A., Chalmers, A. C., Clulow, J., Clulow, S., Cross, P., Gould, J. A., Griffin, A. S., Heurich, M., Howe, B. K., Jachowski, D. S., Jhala, Y. V., Krishnamurthy, R., Kowalczyk, R., Lenga, D. J., Linnell, J. D. C., Marnewick, K. A., Moehrenschlager, A., Montgomery, R. A., Osipova, L., Peneaux, C., Rodger, J. C., Sales, L. P., Seeto, R. G. Y., Shuttleworth, C. M., Somers, M. J., Tamessar, C. T., Upton, R. M. O., \& Weise, F. J. (2019). Reintroducing rewilding to restoration - Rejecting the search for novelty. Biological Conservation 233, 255-259.

IUCN/SSC. (2013). Guidelines for reintroductions and other conservation translocations. Gland, Switzerland: IUCN Species Survival Commission. 
Kasperczyk, B. (1987). The expansion of beaver Castor fiber L. in Europe in the 20th century. Przeglad Zoologiczny.

Krasińska, M., \& Krasiński, Z. A. (2013). European Bison. Berlin, Heidelberg: Springer Berlin Heidelberg.

Macdonald, D. W., Tattersall, F. H., Brown, E. D., \& Balharry, D. (1995). Reintroducing the European beaver to Britain: Nostalgic meddling or restoring biodiversity? Mammal Review 25, 161-200.

MacKinnon, K. (1978). Competition between red and grey squirrels. Mammal Review 8, 185190.

Miller, K. A., Bell, T. P., \& Germano, J. M. (2014). Understanding Publication Bias in Reintroduction Biology by Assessing Translocations of New Zealand's Herpetofauna. Conservation Biology 28, 1045-1056.

Pedersen, P. B. M., Ejrnæs, R., Sandel, B., \& Svenning, J.-C. (2019). Trophic Rewilding Advancement in Anthropogenically Impacted Landscapes (TRAAIL): A framework to link conventional conservation management and rewilding. Ambio.

Perez, I., Anadon, J. D., Diaz, M., Nicola, G. G., Tella, J. L., \& Gimenez, A. (2012). What is wrong with current translocations? A review and a decision-making proposal. Front. Ecol. Environ. 10, 494-501.

Perino, A., Pereira, H. M., Navarro, L. M., Fernández, N., Bullock, J. M., Ceaușu, S., CortésAvizanda, A., Klink, R. van, Kuemmerle, T., Lomba, A., Pe’er, G., Plieninger, T., Benayas, J. M. R., Sandom, C. J., Svenning, J.-C., \& Wheeler, H. C. (2019). Rewilding complex ecosystems. Science 364, eaav5570.

Pettorelli, N., Durant, S. M., \& du Toit, J. T. (2019). Rewilding. Cambridge University Press. 
Pettorelli, Nathalie, Barlow, J., Stephens, P. A., Durant, S. M., Connor, B., Schulte to Bühne, H., Sandom, C. J., Wentworth, J., \& du Toit, J. T. (2018). Making rewilding fit for policy. Journal of applied ecology 55, 1114-1125.

Pucek, Z., Belousova, I. P., Krasiński, Z. A., \& Olech, W. (2004). European bison: status survey and conservation action plan. IUCN Gland, Switzerland and Cambridge.

Robert, A., Colas, B., Guigon, I., Kerbiriou, C., Mihoub, J.-B., Saint-Jalme, M., \& Sarrazin, F. (2015). Defining reintroduction success using IUCN criteria for threatened species: a demographic assessment. Animal Conservation 18, 397-406.

Røed, K. H., Bjørnstad, G., Flagstad, Ø., Haanes, H., Hufthammer, A. K., Jordhøy, P., \& Rosvold, J. (2014). Ancient DNA reveals prehistoric habitat fragmentation and recent domestic introgression into native wild reindeer. Conservation genetics 15, 11371149.

Sarrazin, F., \& Barbault, R. (1996). Reintroduction: challenges and lessons for basic ecology. Trends in Ecology \& Evolution 11, 474-478.

Sarrazin, F., \& Lecomte, J. (2016). Evolution in the Anthropocene. Science 351, 922-923.

Schönfeld, F. (2009). Presence of moose (Alces alces) in Southeastern Germany. European Journal of Wildlife Research 55, 449-453.

Seddon, P. J., Armstrong, D. P., \& Maloney, R. F. (2007). Developing the Science of Reintroduction Biology. Conservation Biology 21, 303-312.

Seddon, P. J., Soorae, P. S., \& Launay, F. (2005). Taxonomic bias in reintroduction projects. Animal Conservation 8, 51-58.

Stahl, P., Vandel, J. m., Herrenschmidt, V., \& Migot, P. (2001). Predation on livestock by an expanding reintroduced lynx population: long-term trend and spatial variability. Journal of Applied Ecology 38, 674-687. 
Stüwe, M., \& Nievergelt, B. (1991). Recovery of alpine ibex from near extinction: the result of effective protection, captive breeding, and reintroductions. Applied Animal Behaviour Science 29, 379-387.

Svenning, J.-C., Pedersen, P. B., Donlan, C. J., Ejrnla es, R., Faurby, S., Galetti, M., Hansen, D. M., Sandel, B., Sandom, C. J., \& Terborgh, J. W. (2016). Science for a wilder Anthropocene: Synthesis and future directions for trophic rewilding research. Proceedings of the National Academy of Sciences 113, 898-906.

Swan, K. D., McPherson, J. M., Seddon, P. J., \& Moehrenschlager, A. (2016). Managing marine biodiversity: the rising diversity and prevalence of marine conservation translocations. Conservation Letters 9, 239-251.

Świsłocka, M., Czajkowska, M., Duda, N., Danyłow, J., Owadowska-Cornil, E., \& Ratkiewicz, M. (2013). Complex patterns of population genetic structure of moose, Alces alces, after recent spatial expansion in Poland revealed by sex-linked markers. Acta Theriol 58, 367-378.

Thévenin, C., Mouchet, M., Robert, A., Kerbiriou, C., \& Sarrazin, F. (2018). Reintroductions of birds and mammals involve evolutionarily distinct species at the regional scale. PNAS 201714599.

Troudet, J., Grandcolas, P., Blin, A., Vignes-Lebbe, R., \& Legendre, F. (2017). Taxonomic bias in biodiversity data and societal preferences. Scientific Reports 7, 9132. 